\title{
Using Social Holistic Approach in Working with Children who are in the War Zone
}

\author{
Yaser Snoubar \\ Ph.D Student. Hacettepe University, Faculty of Economic and Administrative Sciences, \\ Department of Social Work, "Ankara”, Turkey \\ yasersnober@hotmail.com \\ Nurdan Duman \\ Professor. Ph. D.Yıldırım Beyazıt University, Faculty of Health Science, \\ Department of Social Work, "Ankara", Turkey \\ nduman@ybu.edu.tr
}

\section{Doi:10.5901/mjss.2015.v6n2s5p231}

\section{Abstract}

Since beginning of the century to the present day, especially in Asia, Africa and Latin American countries in particular, the conflict violent and war still continues in many parts of the world. These events have a devastating effect to the whole communities. But children as silent victims, during and after these events are exposed to all kinds of neglect, abuse, death and human rights violations represent a major victimization. Living in conflict and violent environment is a tragic event for children and living in this environment, has negative effects on children's physical and psychosocial development. Many disciplines contribute to reduce or eliminate these negative effects. However, social work as distinct from other disciplines has multi-level interventions in order to find a solution to the problem at individual and community levels, as well as national and international level by using a holistic approach to reduce or eliminate the effects of violence and conflict on children. The social worker in this case of such conflict and violence and in particular to carry out work with children required to have special knowledge and skills. These interventions to protect children during and after the conflict realized by using various different skills. Gradually, provide services to children in safe places such as food, drink and services eliminate health problems, in accordance with protect the rights of children in conflict and violence. In the second stage; provide rehabilitation services to children who have been exposed to or witnessed violence and conflict events, lost one of their family members, who entered prison and lived in worst conditions and crippled. The third stage is the stage of the reconciliation. At this stage, social worker plays the role of mediator and prepares the ground for reconciliation to protect children on both sides of the conflict and violence. In this paper, will discuss how to implement interventions to address this issue with discusses Palestinian children, who are living on violence and conflict environment since many years as an example.

Keywords: Social Work, War, Conflict, Violence, Reconciliation

\section{General Situation of Children During and After the Wars, Conflict and Violence}

In today's world, millions of children are directly or indirectly becoming victims of war and or acts of terrorism. The political conflicts, civil wars, and terror are causing children's death, injuries or disabilities. In such cases children lose their parents, relatives and friends. They also undergo through physical, emotional or sexual abuse and deprived of education and other social structures [7]. The UN Secretary General's Report to the 59th General Assembly on Children and Armed Conflict in 2005 outlined practices constituting violations against children as follows: Killing or maiming of children, Recruiting or using child soldiers; Attacking schools, churches, mosques, or hospitals; Raping children, or committing other acts of sexual violence against them; Abducting children and Denying humanitarian access to children [8].

When looking at the problems that children experience during and after the conflict and violence, they can be summarized as follows:

\section{Child Abuse and Neglect}

War and the great social conflicts, are counted as factors from the social factors that cause child neglect and abuse. For being war and civil conflict exceptional situations, while the negatively impacts on the ability of parents caring for children on the one hand, also to be caused increasing tensions related to family life on the other hand, in this case, have 
negative effects on children. Hence the war is among the important risk factors in child abuse and neglect [17]. In this context, children during and after the events of war and conflict, remain open to all kinds of abuse and neglect especially, sexual abuse, trafficking and abduction of children. Children's living in war environment and refugee camps leads them to remain at risk of neglect and abuse as victims as well as being used as shields. Especially children who are abused as shields when they arrested by the occupation forces is a common condition suffered sexual and physical abuse in prison.

At this point, there are no any sanctions of international agreements and organizations responsible for protecting children who are in war environment, from exposed to neglect and abuse in the war environment, is an important issue that attracts attention. This is due to the existing laws might not be operating sufficiently in practice this means the neglecting the children.

\section{Health Condition of Children}

It has to be known that children who are living in war and conflict environment experience both psycho-social and serious health problems as a result of being witness to acts of violence. Some of these problems are listed as; disability as a result of serious injury, the loss of children's lives during surgical operation as a result of not being able to provide the drugs to injured children or prevention from accessing the drugs by the children and the lack of medical supplies.

These children, who are living in unusual situations of war, experience Post-Traumatic Stress Disorder (PTSD) especially when the safe places such as schools, mosques, churches that they took refuge are attacked and transformed into dangerous places. Also, some health problems expected such as death, injury, disability, illness from lack of food and beverages, can occur frequently for children living in war and conflict environment.

\section{The Use of Children as Soldiers}

Use of children as soldiers in war and conflict in torn societies, is a widespread and universal problem. However, the ongoing civil war and conflicts in African countries has become a social and political phenomenon and symptoms of it appears to be destructive, complex and common [8]. Child soldiers experience various psychological, social and physical problems such as trauma, depression, anxiety, learning problems, attention disorder, Post Traumatic Stress Disorder (PTSD), dietary deficiencies, infectious diseases [12]. Even when children are not used as soldiers, using them as shields in order to resume the events of conflict is widespread.

The International Conventions in Line with Protection of Children Who are in Conflict and War Zone and the Execution of these Conventions

Conflict and wars across the globe, are a situations that violates in heavy manner human rights and in particular children's rights. In such cases, using the children as soldiers or shields, and consequently death of them, physical injuries, experiencing psychosocial problems, entering prison, living in poor conditions are some of the expected results. In this direction, they are just international arrangements and intervention to protect children. Although there are many national and international regulations to protect children in situations of conflict and war, there is no visible serious application of these laws that can prevent children's participation in the events of conflict and war, and preventing damage to the children. In such cases, a look at the decisions of the courts and international treaties relating to the protection of children in armed conflict and to prevent the participation of children in armed conflict shows the inadequacy of the applications in this regard.

Historical developments in international law on the prohibition of military mobilization of children date back to the 1970s. Along with giving concrete results of initiatives in the international arena regarding children's rights, the international community's interest in this issue has increased [3].

\subsection{Convention on the Rights of Children}

Based on the statement of Article 38 of the Convention on Child Rights, "In accordance with their obligations under international humanitarian law to protect the civilian population in armed conflicts, States Parties shall take all the feasible measures to ensure protection and care of children who are affected by an armed conflict" [16], the need for international cooperation in the protection of these vulnerable children has become an indisputable fact.

Today, UN resolutions, 1949 Additional Protocols of the Geneva Conventions, Statute of the International Criminal Court and their decisions and Special Court of Sierra Leone decisions are the most important international arrangements regarding the use of child soldiers [3]. In this context, the most important regulations for the protection of children in international law are: 


\subsection{Additional Protocols of the Geneva Conventions of 1949}

The first regulation on the prohibition of military mobilization of children, can be found it in protocols I and II additional to the Geneva Conventions. In the 14th article of Geneva Convention which was signed in 1949 for the protection of civilians in war, it counted children among those who need special protection. The additional one in 1977 has been updated in the first protocol. According to this, passing provision in the article 77 of 1 st protocol is as follows: "The conflict parties shall take all measures to ensure that children under the age of 15 do not participate directly in hostilities; in particular shall prevent these children from taking part in the armed forces. However, people who are over the age of 15 but under the age of 18 in the case of taking them part in combat as soldiers, the conflict parties must try to demonstrate all the necessary measures to give priority to older children." [3].

\section{The Effects of Conflict and Violence on Children's Development}

Everyone is not equally affected by violent event or disaster and all disasters are not devastating on an equal footing in terms of the psychological. For instance, refugees from war, political oppression, or political violence are also at high risk of adverse effects. In addition, the effect of the events that may have driven them from their homes, negative experiences in shelters and refugee camps (e.g., malnutrition, widespread infectious disease, rape and other physical assaults) may themselves produce adverse psychological effects and psychological disorders [6]. Mental and Physical health are linked and interact with each other. Mental health affects physical health and physical health also affects psychosocial development [10]. Children who are living in violent environments and have been exposed to violence generally show signs of Post-Traumatic Stress Disorder (PTSD), which may be modified because of their age. Clinical evidence exist for disrupted patterns of eating and sleeping, difficulties in meeting and relating, anxious reactions, fearfulness, and reexperiencing the trauma, evidenced by behaviors as children cannot yet use language [11]. In general, exposure to violence in the social environment is a serious and significant risk factor for the development of psychopathology in children and adolescents. Studies documenting relations between violence exposure and aggression, depressions, anxiety, post traumatic stress (PTS) symptoms, and academic difficulties [5]. Many factors have a negative impact on children's psychosocial adjustment. Conflict and war events form these factors. Due to children being forced to struggle with living in violent environments like this, it is an unavoidable reality to live in psychological and social problems. Therefore, the negative effects of conflict and violence incidents on the psychosocial development of children are quite high.

Social Work Intervention for Children who are in Conflict and Violence Environment and Special Knowledge and Skills of Social Workers Required

There are many services social work profession can execute in the field of child welfare. Social work interventions for solving children's psycho-social problems that arise after the war and conflict can be realized at micro, mezzo and macro levels. These works are usually carried out in shelters, refugee camps and schools. At the micro level, social workers provide psycho-social support to children who lived in violent environments, this first method of aid those children need it. Social workers, who provide psycho-social support to these children, must have knowledge and skills on issues such as; cultural environment where children live, psycho-social development of children and adolescents, the methods of communicating with children, allow opportunities to children to express their feelings and to live emptying the emotional, and not talk about death.

War and conflict situations need to be addressed as crises situations as a result of devastation caused by it in the psycho-social and environmental conditions. In these violent environments, people especially children, are faced with lose are compelled to confront a sense of losing that extends from their material goods they have, as well as their loved ones. We need an urgent intervention to save children from violent events and from these situations prevent the psychosocial development of children. This intervention is crisis intervention, with a wide application area, that dating back from individual crises to social crises.

Psychiatrist expert Richman [13] has over 30 years of experience in working with children exposed to violence, whose book "Communicating with Children - Helping Children in Distress" has been a guide book for specialists working in different fields, specially to develop listening and communication skills for conflict situations and emergency workers, to determine the problems of children with special needs, to understand the different cultural ways of struggle with communication and stress and overcome communication barriers. Richman [13], in this study, listed the information that experts should have, to communicate with children and to help children who are living in danger, as follows:

- Communicate with children of different ages (here the skills must expert have been; listening, using body language, chatting) 
- Meet with a child; establish a relationship of trust and being careful to his feelings

- Monitoring children

- Providing support and consultancy services for children (to comforting, understanding children tantrums and acceptance)

- Talking to children about death

- Methods of working with children who became disabled as a result of war and violence

- Communicate the child's family.

Social worker who are taking advantage from this methods Richman's has to offer to experts who are working in this field, can work with children affected by violence and can effectively provide psycho-social support to them. Children having lived in an environment of violence may cause learning violence. Therefore, this situation resulting in children resort to violence to solve their problems shows that the child's solving problems skills was influenced negatively. In order to correct the negative effects of children responses related to trauma that children experience after the violence on their psychosocial adaptation, social workers can provide care and rehabilitation services in both the individual and community levels. There are many psycho-social support programs for protection children from violence. These programs include services intended for psycho-social adoption of children who were exposed to violence. For instance, (Save the Children) describes three approaches regarding the content of the program [9] Approaches taken based on these programs can be expressed as follows:

- Curative programmes: are carried out in order to address diagnose and treat psychological effects of violence and trauma on children.

- Preventative programmes: that seek to prevent further psychosocial deterioration of children who have seen violence.

- Programmes that promote healthy psycho-social development: intervene in children by working together with parents, children and caregivers, this aims at helping children develop efficiently their coping skills towards negative life events. These programs are based on the developmental approach. These programs often are carried out in activities such as:

- Community-based recreation, cultural, sports and similar activities provide opportunities for children to participate and to ensure their return to normal life as soon as possible;

- As a guide, provide psycho-social support and financial support to parents.

Strengthening the role of schools as multifunctional centers. Some development programs focus on the returning back to normal the stable living conditions and the normalization of living conditions. Other programmes are more specialized, helping groups of children deal with specific situations through various methods, which often include creative means such as drawing and playing. These programs aim to strengthen children's social environment, helping teachers and parents to support their children, and thus focus on increasing the level of knowledge. It is intended for future development programs such as the psycho-social well-being of children.

- The adoption of a broad community development strategy is the most effective way for the well-being of children who are affected by forced migration, conflict and violence, [1] it can be performed in the following steps:

- enables individuals in the communities to begin to restore control over their own lives;

- facilitates the development of community facilities, especially available to children such as schools, preschools, health facilities and recreational activities;

- helps to restore or create a range of other supportive structures and organizations that support the children within the community;

In this context, psycho-social interventions must take place at the community level. These interventions are called (Non-specific psychosocial Interventions). These interventions include work such as stopping ongoing conflicts and providing shelter and safe areas, prevention of the current tensions as much as possible. These interventions provide repair or re-activation of the important curative and protective factors such as active participation, education and coordination of families to the improvement of community psycho-social well being.

There are a lot of factors that affect re-establishment of the network of social relations and psycho-social recovery in communities living in war and conflict environment. Death separation, alienation, and other losses experienced in the war, causes damage to the social values and customary practices. All they increase the psychological and social impact of war on children's mental health. Interplay of all these factors affect both a child's understanding and perceptions as well as lead to the emergence of some special symptoms in child. In order to ensure that restart the children, psychosocial health and a stable environment, require the provision secure environment to adult care, security, education, 
participate in social activities and games to play.

Due to increasing awareness of these aspects of the recovery process, many NGOs have implemented programs of psychosocial support that specifically address the needs of families and children. Some of these programs focus on educating and supporting parents and teachers so that they in turn can support the children, whereas other programs involve direct work with children to help them process their traumatic memories through drawings, play or talking about what has happened. Although restoration initiatives have utilized both population-based and individualized approaches, they may necessarily involve simple and direct approaches due to limited resources and the large numbers of affected individuals. These may include, for example, training programs and initiatives aimed at educating community leaders to help in the psychosocial healing process. Individualized interventions are usually introduced after population based ones because of emergency conditions and the sheer numbers in need [4]. In general, the services provided to children affected by the events of war and conflict, are presented in the form of program or project. Social worker can be a part of these programs and projects, so the social worker, in order to eliminate the factors that impede children's psycho-social development, contribute in providing psycho-social adaptation of children using different techniques and provide psychosocial support.

Psychosocial refers to the child's inner world and the relationship with his or her environment. Psychosocial support is important in order to maintain a continuum of family and community based care and support during and after humanitarian crises like war and conflict and to prevent immediate or long term mental health disorders. Hence the access to humanitarian assistance and safety and security for the population is the cornerstone of psychosocial support during humanitarian emergencies. An important shift has taken place in psychosocial interventions from an individualized approach to a community based approach focused on enhancing the resiliency of children and families. The aim of psychosocial interventions is to address children's issues and needs in a holistic manner and to place psychosocial interventions inside wider developmental contexts such as education or healthcare. This will create an integrated developmental approach to promoting psychosocial wellbeing. To provide psycho-social care and support to children requires strengthening the capacity of teachers, caregivers and friends [2]. Here also should be noted that the role of schools in providing psycho-social services. Schools can play an important role in identifying and monitoring vulnerable children, enhancing their understanding of events, and providing personal support [1].

\section{Case Study: Working with Children who are in Palestine's Conflict Environment}

Majority of the children that are victims of the long-standing and on-going crisis and wars in the Middle East are experiencing partial education, health, care, psychosocial, and adaptation problems. To understand and grasp the real problems of these children, discussing Palestinian children who are victims of war and conflict for decades and taking them as an example can enrich our position.

Historically, children had been major victims of these events that began in 1948 and still ongoing until now. These events are not events that occurred and ended in certain date so problems caused by war and conflict since then are devastating effects on all generations. Undoubtedly, unless children are provided with peace the future generations will continue to be adversely affected.

Palestinian children witnessed and have been exposed to all kinds of violence as they grew up in war environment which started in 1948 and continue till the present day. There are some problems that Palestinian children, are facing due to the living in war environment. These problems as follows are [15]:

Death: in never ending war environment in Palestine there have been many massacres and the number of children who died in this massacre is quite high. Survive is the biggest problem of Palestinian children who are living in war conditions. Palestinian children are faced with death anytime and anywhere: at home, at school, on the road, in the hospital. In Palestine many homes and schools have been destroyed by bombs thrown by Israel. Hundreds of children have died under the demolished houses. Walking on the road has become the target of bullets fired by Israeli soldiers. Some children die from pain when removing the bullets that hit their bodies as a result of inability to receive the drug aid from other countries and power failure in hospitals.

Detention: Palestinian children are imprisoned for throwing stones at Israeli soldiers in inhumane conditions. Children detainees are exposed to intimidation, ill-treatment and torture during the arrest and detention. Despite the young age of these children are being tried in Israel's military courts. These children face many problems after their release from prison. These include psychological problems, living problems in adapting to family and school, fear of detention again, health problems and occurring problems from sexual abuse and torture in prison. Due to these problems children remain face to face with social isolation because they cannot adapt to society in their real-life.

Abused children from political parties: some of the political parties in Palestine are using children in combating 
Israeli soldiers to achieve its objectives. Some of the children who were used have died or became disabled; some others arrested and were tortured. These children, who combat the occupying forces, generally live in lack of education and poor refugee camps.

Child Labor: poverty that has become more concrete with economic problems, unemployment, low wages, lack of social security, the bad and unbalanced diet, low living standards and other variables' effects can be observed on the life of individuals, family and community. As a result of poverty in Palestine as well as in other countries, it is common to find children begging, selling handkerchiefs, working in industry, organizations, or as car launderer. However, a new way of working was born in Palestine, due to the war and the siege. This can be defined as "work in tunnels". The materials brought by traders from Egypt such as flour, sugar, bread, thinner are carried by children throw tunnels. Due to the physical features of the children they can move freely in tunnels, children contribute to the family with the little money they earn from this work. Some children who are working in the tunnels know their parents were killed or had been disabled in the war.

Experienced health problems due to the siege and war: thousands of children became disabled in the war in Palestine. Some of these children will be disabled for the whole life. Children face more health problems because they have no treatment that they need since they remain under siege that causes poor nutrition and lack of medical supplies. It should be known that children experience very negative traumatic conditions because they live in constant fear as a result of events they witnessed, as well as witnessing the death of all or some of their family members.

Homeless children: the destruction of the homes of children that not only for the meet of their need for housing, but also feeling of being security, is another traumatic event for the children and their families and often takes a long time to overcome. Save the Children UK [14] has done a research about BROKEN HOMES Addressing the Impact of House Demolitions on Palestinian Children \& Families. The study found that $97 \%$ (92 out of 95) of mothers and fathers whose homes were demolished suffer from trauma-related symptoms. Problems such as depression and isolation in children who had witnessed the destruction of their homes can be observed

Immigrant children: It can easily be observed that children living refugee camps live in extremely poor conditions. Staying too long in these conditions causes negative impact on children's mental and physical health.

Violence in schools due to war and conflict: school children in Palestine still under the influence of the war they see in the street can apply the pattern of violent behavior against each other in school. It is known children are affected by the massacres they saw or experienced and cannot concentrate in classes. Children live in fear that the missile will strike at their school any moment.

Status of trauma in post war children: the effect of war environment on children and the trauma it causes differs from child to child. Some of the children are afraid of the sounds of planes and tanks, and don't feel self-confident. Children hearing these sounds fear that they are going to die at any time. Children who witness death of family members or familiar people in this conflict and war are at greater risk of having psychological problems.

When looking at problems that arise for children living in war environment, it is possible to clearly see that they are in the situation of all kinds of national and international neglect and abuse. Despite the existence of national and international associations and organizations that are responsible for protecting children as well as contracts and agreements that were signed in and came into force, children's rights are still being violated.

\section{Conclusions and Recommendations}

Protection of children in war and conflict situations, as well as a human task is a responsibility of the social work profession. It is a must to intervene to this problem in both in terms of existing international legal agreements at the macro level and preparing the ground of reconciliation at the community level. The roles and responsibilities of Social Work in this issue can be briefly summarized as follows:

Being with the children during the war and conflict; placing them to safe places, distance them from the events of the conflict in cooperation with existing national and international associations and organizations in war zones to protect the children.

Provide services such as food and beverage, and services to eliminate health problems in order to determine the status of children.

In order to eliminate the negative effects of war on the psychosocial development of children, effort of psychosocial support, the release of children who from prisons of conflict parties and ensure their participation in rehabilitation programs after the war.

Provide support to social workers who are working in war and conflict environment based on the principle of ("help to helpers"), by creating a social worker team from countries that support peace. 
In cooperation with the media, to run programs that provide awareness in and inform parents about the effects of violence on children and prevent the families to cause their children to participate in acts of violence.

Make meetings and negotiations on both sides setting the ground to begin peace talks and to prepare room for reconciliation.

Take an active role as a profession with the mission to help people in order to remind the international agreements that are responsible for protecting the children in war environment in the event of any war in the world,

Take the problem to international platforms, in order to intervene in harm of children who are in war environment, organization of international conferences to attract the attention of the world towards this subject and in the light of the results of these conferences guide the formation of a committee at the international level to protect the rights of children who are living in this environment and

Initiate work in order to protect children in war and conflict environment and prevent harm in this environment by creating special camps in war zones, under the protection of the United Nations.

\section{References}

Action for the Rights of Children (ARC)., 2001, Foundations - Working with Children, http://www.unhcr.org/3bb822b34.html.

Action for the Rights of Children (ARC)., 2009, Resource pack study material: Foundation module 7: Psychosocial support, http://www.unhcr.org/4c98a5169.html.

Azarkan, E., 2009, Protection of Child Soldiers in the Framework of International Agreements and International Decision of the Court, Journal of International Law and Politics., 5(19), pp. 89-107.

Barenbaum, J., Ruchkin, V., Stone, M. S., 2004, The psychosocial aspects of children exposed towar: practice and policy initiatives. Journal of Child Psychology and Psychiatry., 45(1), pp. 41-62.

Dubow, A. F., Boxer, P., Huesmann, L. R., Shikaki, K., Landau, S., Gvirsman, S. D., Ginges, J., 2009, Exposure to conflict and violence across contexts: relations to adjustment among palestinian children. Journal of Clinical Child \& Adolescent Psychology., 39 (1), pp. 103-116.

Ehrenreich, J. H., McQuaide, S., 2001, Coping with disasters a guidebook to psychosocial Interventıon, New York.

Erden, G., and Gürdil, G., 2009, Trauma reactions observed in children and adolescents after the war experiences and psychosocial support suggestions, Turkish Psychological Articles., 12 (24), pp. 1-13.

Francis, D. J., 2006, "International Conventions and The Limitations For Protecting Child Soldiers In Post-Conflict Societies In Africa." Paper Presented At Conference: Phase II: Protection: Children and War: Impact, Protection and Rehabilitation. January 14-15, 2006, Los Angeles, California. Accessed 15th August 2006, from

www.arts.ualberta.ca/childrenandwar/papers/Children_and_War_Phase_II_Report.pdf.

Kalksma, Van., and Lith, B., 2007, "Psychosocial interventions for children in war-affected areas: the state of the art." Intervention., 5(1), pp. 3-17.

Metraux, J. C., 1995, "Children Victims Of War: Manual Of Psycho-Social Care For Health Aides", Refugee Policy Group, Sweden, Volume 1.

Osofsky, J. D., 1995, "The Effects Of Exposure To Violence On Young Children" American Psychological Association., 50(9), pp. 782788.

Polat, O., and Güldoğan, E., 2010, "Child Soldiers: Psychological, Social and Physical Issues", Journal of International Security and Terrorism., 1(1), pp. 105-124.

Richman, N., 1993, "Communicating with Children: Helping Children in Distress", ISBN: 1-870322-49-5, ISSN: 0966-6982 Save The Children Development Manuals.

Save the Children UK., 2009, was do research about BROKEN HOMES Addressing the Impact of House Demolitions on Palestinian Children \& Families, Palestine. http://www.savethechildren.org.uk/sites/default/files/docs/Broken_Homes_English_low_res.pdf

Snoubar, Y., 2010, Problems of Children who are in War Environments and Social Work (Palestine as an Example)", Social Work, association of social workers publication., Turkey, 20, pp. 13-17.

UN., 1989, The Convention on the Rights of Children.

World Health Organization., 2002, "Child abuse and neglect by parents and other caregivers", World Report on Violence and Health, Geneva". 